
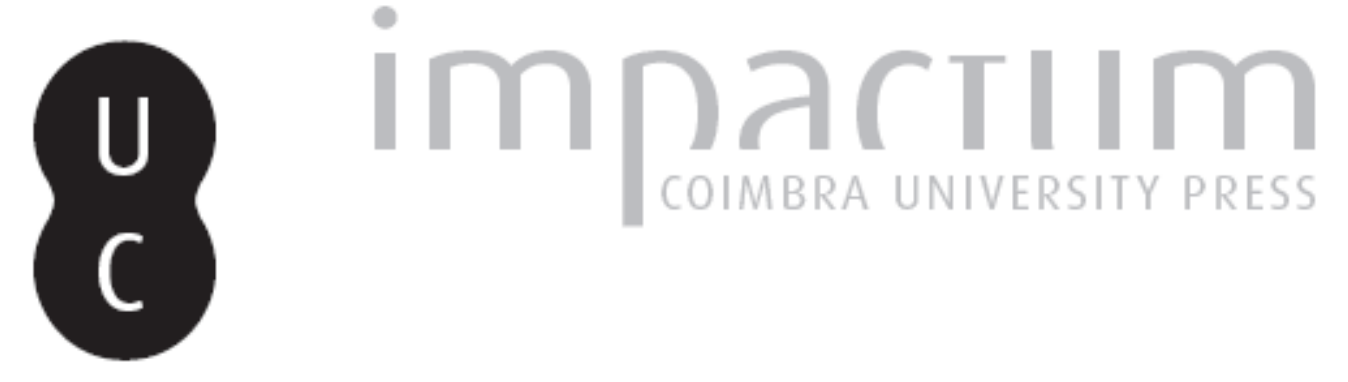

\title{
O Corporema da casa portuguesa ou repensar o problema da casa portuguesa de
} Fernando Távora

\author{
Autor(es): $\quad$ Miguel, Patrícia
}

Publicado por: Editorial do Departamento de Arquitetura

URL persistente:

URI:http://hdl.handle.net/10316.2/37328

DOI:

DOI:http://dx.doi.org/10.14195/1647-8681_3_13

Accessed : $\quad$ 26-Apr-2023 08:45:08

A navegação consulta e descarregamento dos títulos inseridos nas Bibliotecas Digitais UC Digitalis, UC Pombalina e UC Impactum, pressupõem a aceitação plena e sem reservas dos Termos e Condições de Uso destas Bibliotecas Digitais, disponíveis em https://digitalis.uc.pt/pt-pt/termos.

Conforme exposto nos referidos Termos e Condições de Uso, o descarregamento de títulos de acesso restrito requer uma licença válida de autorização devendo o utilizador aceder ao(s) documento(s) a partir de um endereço de IP da instituição detentora da supramencionada licença.

Ao utilizador é apenas permitido o descarregamento para uso pessoal, pelo que o emprego do(s) título(s) descarregado(s) para outro fim, designadamente comercial, carece de autorização do respetivo autor ou editor da obra.

Na medida em que todas as obras da UC Digitalis se encontram protegidas pelo Código do Direito de Autor e Direitos Conexos e demais legislação aplicável, toda a cópia, parcial ou total, deste documento, nos casos em que é legalmente admitida, deverá conter ou fazer-se acompanhar por este aviso.

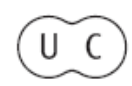




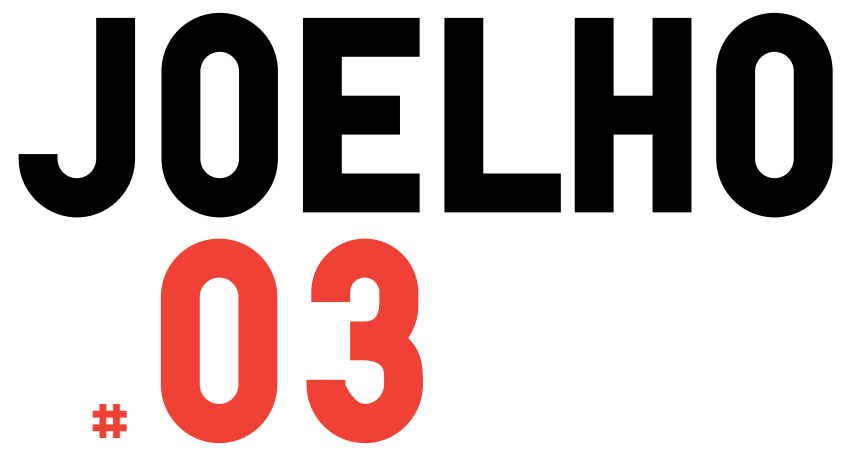

\section{VIAGEM-MEMÓRIAS: APRENDIZAGENS DE ARQUITECTURA}

Coordenação:

Alexandre Alves Costa

Domingos Tavares

Exposição Viagem

Exposição Memórias

Luis Mansilla

Alexandre Alves Costa

Domingos Tavares

SCA FoL DiNG
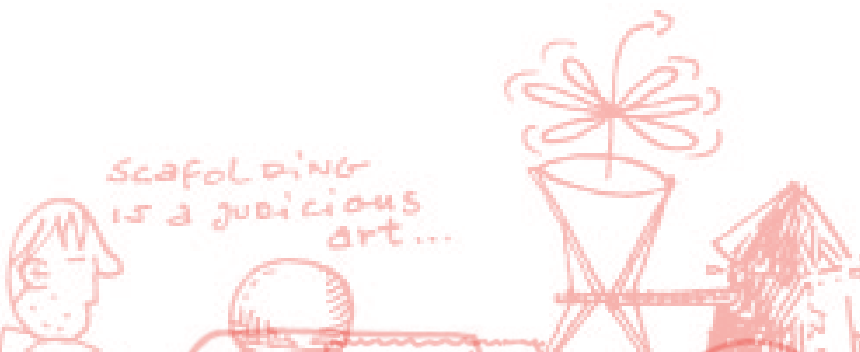

Jorge Figueira

José Miguel Rodrigues

José António Bandeirinha José Fernando Gonçalves

Paulo Providência

Gonçalo Canto Moniz Armando Rabaça

Patrícia Miguel

Bruno Gil

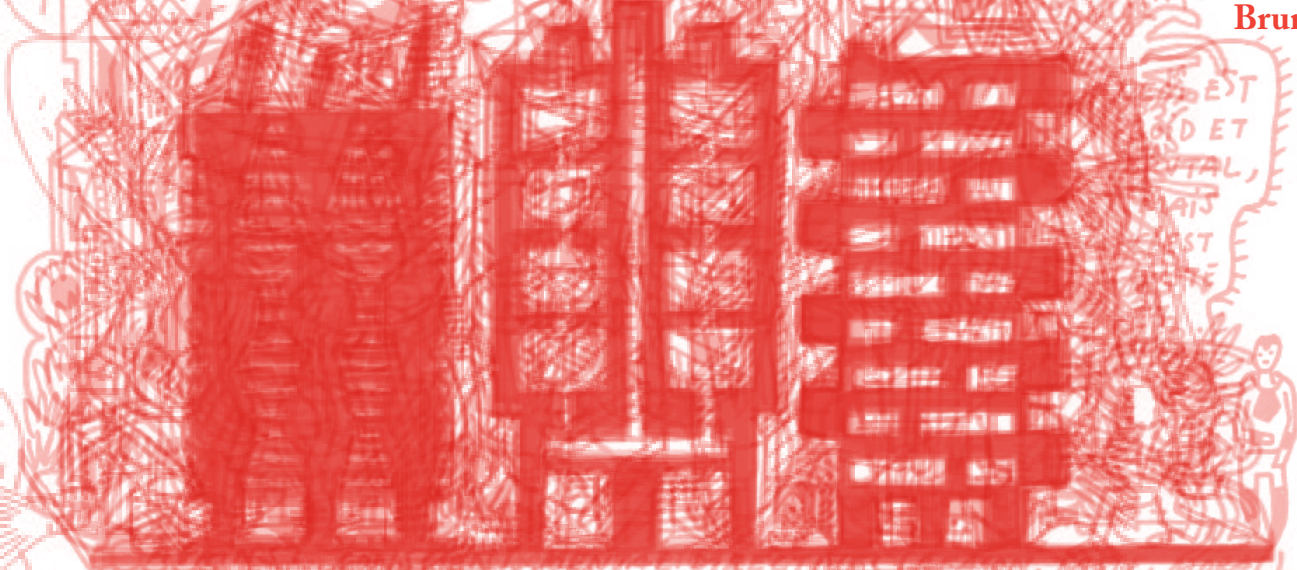

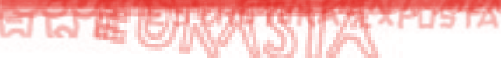




\section{Patrícia Miguel \\ O Corporema da Casa \\ Portuguesa ou repensar \\ O Problema da Casa \\ Portuguesa de Fernando 'Távora}

Arquitectura $\dot{e}$ a arte de fazer coincidir as formas de uma civilizáăáo com o seu conteido.

W. LESCAZE

$$
\begin{aligned}
& \text { Pase } \\
& \text { Paviricie }
\end{aligned}
$$

- Ener diquatie e

parabers pele avitical

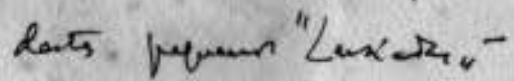

小

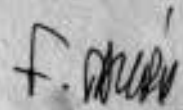

$$
\text { Critere } 41.97
$$

CADERNOS DE ARQUITECTURA N.: 1

GRGANIZACAO $E$ EDICTO DE MANUEL JOAO LEAL.
(III)

$15 \cdot 10.96$

0 PROBLEMA DA CASA PORTUGUESA

Por Fernando Távora

o País constrói. O País constrói muito. O Pais constrói cada ves mais.

Levantam-se casas, fabricas, escolas - nas cidades, nas vilas, nas aldeias. Mas fica-se cheio de dor ao verificar que essa enorme acfividade construtiva tem resultado falseada na sua expresșđo arquilectónica.

Os processos de construcão, no aspecto temico como no financeiro, vão adaptando-se, embora custosamente, ds necerssidades. Mas o estito enoscido do Povo e da Terra com a expontaneidade e a vida duma flors, o ccarácter novo das condicōes novass - esses nāo af́arecem. Preconceitos bdsicos tim viciado as tentativas mais bem intencionadas para os fazerem surgir.

Todavia, um caminho ndo foi ainda trilhado: o que i apontado no presente ensaio, precisamente o vinico que pode levar ao florescimento de uma arquitectura portuguesa viva, $O$ seu autor, Fernando Tavora, finalista de Arquitectura ma Escola de Belas Artes do Porto, aponta, com coragem e convicpäo, os erros do fresente e os caminhos do futuro.

elmpōe-se um trabalho sério, conciso, bem orientado e realistas, animado for um espirito novo. CTudo há que refazer, começondo pelo princípios. 


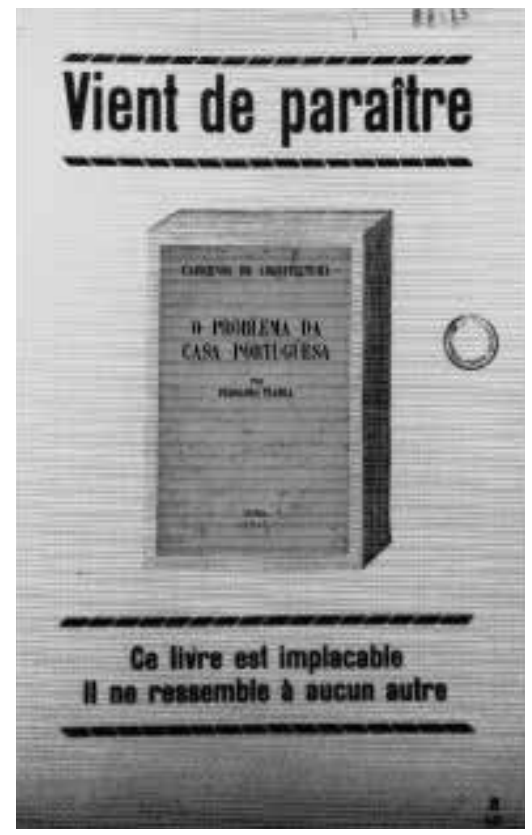

O corporema seria um conjunto de signos que, emancipandose do reservatório inesgotável de sentido que o corpo constitui, se autonomizaria, mantendo todavia relações de afinidade formal e conceptual [...] com o corpo mãe.

Paulo Cunha e Silva (1999, p.55)

\section{Il est des parfums frais comme des chairs d'enfants, Doux comme les hautbois, verts comme les prairies, - Et d'autres, corrompus, riches et triomphants,}

\section{Ayant l'expansion des choses infinies ${ }^{1}$ \\ Charles Baudelaire (1993, p.58)}

Preâmbulo pessoal, Correspôndencias, ou Tudo há que refazer começando pelo princípio

Quando, em Outubro de 2003, o arquitecto Mário Krüger, numa aula de Teoria em Arquitectura, ${ }^{2}$ mostrava o cartaz Vient de paraître, pensei substituir naquela imagem a capa do livro de Le Corbusier pela capa d'O Problema da Casa Portuguesa de Fernando Távora (1947). ${ }^{3}$ O opúsculo de Távora, sendo mais fino do que Vers une Architecture, ficaria ainda melhor inserido na estratégia publicitária de fingimento de espessura operada por Corbusier. ${ }^{4}$

Juntava-se a isto a dedicatória que em 1997 Fernando Távora escrevera no meu exemplar d'O Problema da Casa Portuguesa de 1947: 'com simpatia e parabéns pela aquisição destes pequenos "Lusíadas"'. A expressão 'pequenos "Lusíadas", ao mesmo tempo que reassociava o texto a uma efectiva estratégia espessante operada intencionalmente pelo próprio Távora, remetia-me ainda para uma interrogação sobre a possibilidade de existência de teorias que, apesar de simples, seriam fundamentais na complexidade própria de uma cultura arquitectónica.

Às questões da retórica e da teoria, que interessavam ao arquitecto Krüger, associei também algumas provocações que lançava Paulo Varela Gomes nas aulas de História da Arquitectura, nomeadamente através do artigo "Untitled: The Housing of Gender" de Mark Wigley (1992). Utilizei esta matéria, a das correspondências entre Alberti, Le Corbusier e Távora, para demonstrar que O Problema da Casa Portuguesa seria uma espécie de tratadema - uma unidade teórica mínima estrutural. Esse foi o primeiro Corporema da Casa Portuguesa, escrito em Dezembro de 2003. ${ }^{5}$

O título $O$ Corporema da Casa Portuguesa surgiu neste e noutro contexto. Quando Paulo Cunha Silva, no Cinema S.Jorge em Novembro de 2003, tentava uma possibilidade de explicação da sua noção de corporema - fazendo-nos perceber que uma orelha isolada, apesar de autónoma, remete sempre para o corpo-mãe (mutilado) sem a existência do qual não existiria ${ }^{6}$ - imaginei que ali se repensava a tal possibilidade de existirem teorias em Arquitectura que, apesar de simples, seriam pertença e estrutura de uma determinada identidade complexa. 
Mas se por um lado o texto de Fernando Távora funcionava como uma espécie de condensador de sentidos contemporâneos, aquém e além da contemporaneidade, parecia simultaneamente estar a tornar-se obsoleto: na livraria XM, em Coimbra, arquitectos tão jovens quanto eu mostravam silos para automóveis e reivindicavam por uma arquitectura nova que contrariasse as tradições e a ideia de 'identidade portuguesa': 'uma arquitectura por exemplo com qualidades de transparência, nos antípodas do Kubler'. Num comentário final, Paulo Varela Gomes viria a dizer que estes jovens são a vanguarda contemporânea, a 'neo-vanguarda'. Esta espécie de separação entre tradição e vanguarda, questionava alguns pressupostos do opúsculo de Távora.

Em finais de 2004 voltei a reflectir O Problema da Casa Portuguesa 'começando pelo princípio'. Entretanto, o ciclo de exposições Influx, Arquitectura portuguesa recente - realizado no Porto entre Março de 2002 e Setembro de 2003 - que já tinha dado alguns motes para o confronto da capacidade teórica do texto de Távora com a contemporaneidade, transformou-se em Metaflux e foi mostrar Duas gerações na arquitectura portuguesa recente à ga Bienal Internacional de Veneza de 2004 . $^{7}$ Metaflux parecia querer reivindicar que 'identidades nacionais' deveriam ser substituídas por uma espécie de supra 'identidade urbana europeia'. Tornava-se então legítima a ainda-curiosidade: Qual é o embate do texto de Távora com a aparentemente-nova consciência de uma necessidade de internacionalização, de uma vontade de "identidade europeia"? Qual é afinal o confronto que se pode estabelecer entre a crítica europeizada/ internacionalizada da arquitectura contemporânea portuguesa e a ideia de identidade inerente ao texto de Távora?

\section{Preâmbulo impessoal}

José António Bandeirinha associa com rigor O Problema da Casa Portuguesa às premissas para a aplicação edificante do pensamento pós-moderno de Boaventura de Sousa Santos e confronta-o com os referenciais Le Corbusier e Movimento Moderno (1996, pp.76-118). ${ }^{8}$ Bandeirinha, a propósito da finalidade genérica com que escreveu Quinas Vivas, refere: 'prendem-se estes objectivos com a necessidade que sinto de transmitir aos alunos a presença de um corpo teórico suficientemente claro e autónomo' (1996, pp.13-15, 14). De facto, em 1993, O Problema da Casa Portuguesa, reproduzido em livro com a obra de Távora, continuava a ser consumido na cultura disciplinar da arquitectura em Portugal. Nesta publicação, o ensaio de Alexandre Alves Costa de 1992, evocava a possibilidade da sua releitura actual, 'a sua continuidade e sua coerência e sobretudo a sua permanente contemporaneidade' (1993, p.17).

O Problema da Casa Portuguesa, nas afinidades com a produção arquitectónica que se seguiu ao Congresso de 48, reivindicava contra o 'regionalismo fascizante' da "Casa Portuguesa" (Tostões, 1997, p.49). No entanto, porque ligado à busca de uma arquitectura encontrada na casa popular, no 'Povo' e na 'Terra', adiantava também a tomada de 
consciência da heterodoxia do Moderno. Torna-se perceptível esta ambivalência do texto de Távora na forma como a sua provocação 'tudo há que refazer começando pelo princípio' é apropriada por Ana Tostões para significar coisas diferentes em diferentes partes d'Os Verdes Anos: ao mesmo tempo que 'aparentemente desprezava compromissos e recusava o valor da história', significava a renovação nas 'preocupações de uma nova geração que vimos interessada na fundamentação histórica e nas raízes orgânicas da arquitectura' (Távora, 1947, p.9; Tostões, 1997, pp.140-141, 159). Seria na abordagem à necessidade de se perceberem os princípios da arquitectura tradicional, cujo grau de antecipação é partilhado pelo arquitecto Keil do Amaral em "Uma Iniciativa Necessária", que O Problema da Casa Portuguesa se torna percursor da realização do Inquérito à Arquitectura Regional Portuguesa. Iniciado em 1956, teria Távora como coordenador da equipa do Minho e seria publicado em 61 nos volumes Arquitectura Popular em Portugal.9

Repensar O Problema da Casa Portuguesa parece assim tratar-se de uma espécie de hermenêutica - porque se tem a consciência de que o carácter dos textos se mede também pelo modo como foram apropriados.

1

Pedro Gadanho e Luís Tavares Pereira, comissários do ciclo de exposições Influx, Arquitectura portuguesa recente, ${ }^{10}$ interrogam na introdução do catálogo: 'Interessará esta escolha a novas audiências ou àqueles ideólogos que propagam a leitura restrita da resistência da arquitectura portuguesa?' Gadanho e Tavares Pereira acrescentam, reforçando a polaridade: 'Antes desta geração assistiu-se à consolidação identitária da arquitectura portuguesa à sombra da genialidade de alguns dos seus protagonistas.' Em Influx defende-se a 'condição nómada do discurso teórico e a circulação facilitada das imagens' que 'promovem, também, um tipo de internacionalismo' (2003, pp.10, 11, 121).

Esta ideia de que a arquitectura portuguesa perde a sua 'consolidação identitária' parece ser reforçada quando os comissários de Influx levam a exposição Metaflux à ga Bienal de Arquitectura de Veneza. ${ }^{\text {" }}$ Gadanho interroga-se se "perante cada realidade e tradição local, não é a identidade urbana europeia aquela que deve ser privilegiada por uma geração que cresce muito mais miscigenada'. O que prevalece é a ideia de que aos vários graus de se "ser estrangeiro" (europeu ou do mundo) se opõe um atávico "ser-se português". De um lado, a mais recente geração de arquitectos 'pacificamente indiferente a valores antes tomados como cruciais ou essenciais', do outro, uma 'pesada, autónoma e academizada tradição arquitectónica portuguesa' (2004, pp.47, 41, 39). ${ }^{12}$

Gadanho acusa as escolas de arquitectura portuguesas de 'malformação hiper-disciplinar', de 'debilidade discursiva', de não promoverem 'a criatividade e o pensamento crítico como ferramentas 
operativas, preferindo antes transmitir - de uma forma presumivelmente não ideológica - uma certa "tradição"' (2003, pp.152, 153). Ricardo Carvalho, no catálogo Influx, acusa uma 'endémica ausência de suporte teórico' na arquitectura portuguesa dos últimos anos e evoca um 'desgaste do "princípio de realidade"': 'o confronto entre o moderno e a tradição vernácula revelou-se central na mais periférica e experimental arquitectura desde a década de cinquenta, onde podemos destacar a obra de Fernando Távora. Mas é a sua superação [...] que conduz os arquitectos contemporâneos a um novo acerto de premissas' (2003, pp.168, 165, 167).

A crítica da arquitectura subjacente às exposições Influx e Metaflux parece reagir contra uma espécie de 'academizada tradição arquitectónica', mas desta, baseada aparentemente nos pressupostos lançados por Fernando Távora no seu manifesto edificante.

'Por estranhos raciocínios estabeleceu-se (é o termo) que a nossa arquitectura "tradicional" era caracterizada por um determinado número de motivos decorativos cuja aplicação seria suficiente para produzir casas portuguesas. Surgiu daqui uma nova forma de academismo, entendendo-se por tal atitude de espírito aquela para a qual a Arte pode codificar-se em formas eternas, segundo regras fixas e imutáveis.'

(Távora, 1947, p.7)

Pode um texto de teoria de superação de academismo ser superado por textos de superação de academismo?

2

A separação entre ideólogos-da-identidade-nacional e nova-geraçãointernacional (ou -europeia?) é metaforizada através do título do artigo no catálogo Influx: "Escassez \& Deslocação". Escassez como a 'desculpa cómoda para a facilidade e para a repetição'; e Deslocação como metáfora para o 'errático, nomádico e eventual' que sugere a 'efectiva e natural superação do fantasma vernáculo' (2003, pp.151-152, 155). ${ }^{13}$

Quer esta insistência na superação do vernáculo, quer a ideia de escassez associada aos academismos que se pretendem, também, superar, acrescentam dúvidas: existe alguma relação entre normativa e escassez? Agudiza-se a pertinência e ambiguidade desta questão se houver uma eventual ligação entre o opúsculo de Távora e algum tipo de construção prescritiva de escassez. Esse elo poderia existir, por exemplo, através do Movimento Moderno, particularmente a partir da influência de Le Corbusier.

Le Corbusier, em "Esprit de Vérité", diz sentir-se movido por uma força de julgamento, um espírito de verdade associado aos seres activos. Távora, movido por semelhante espírito de julgamento, usa exaustivamente termos como falsa, superficial, sem nexo, sem lógica, mal, grave doença, doença ainda mais grave, princípio de caos, muito difícil 
de banir.... para se referir àquilo que considera a 'mentira arquitectónica que caracteriza as más obras e os maus artistas' (1996, pp.165-184,182). ${ }^{14}$ Távora exalta a "ccasa popular" e 'apaixonando-se pela realidade portuguesa, apaixona-se também pelos saberes que lhe permitirão conhecê-la melhor propondo, com veemência, o lançamento dos "estudos" que veiculem eficazmente esse conhecimento' (1947, p.8).15 Em "Iconoclastes encore: l'homme, l'homme tout nu" Corbusier apela para a investigação contra a parcialidade, como forma de se restabelecer a verdade. Le Corbusier exalta o corpo nu como algo respeitável e associa um cérebro a este corpo nu - a inteligência de ser pensante (1996, pp.2224). Em "Le Lait de Chaux; La loi du Ripolin", Corbusier associa o branco da cal à supressão do equívoco, à atenção reforçada sobre o objecto puro, perfeito e completo. Corbusier faz a exaltação do indivíduo bom juiz, que sabe distinguir o que é supérfluo ou o que é artificial, e associa o branco à clareza para se poder ver e decidir: 'o branco da cal é extremamente moral'. O objecto perfeito seria um organismo vivo, porque animado pelo espírito da verdade; e a lisura e a cal seriam as características desse objecto verdadeiro (1996, pp.185-195, 193). ${ }^{16}$

Mark Wigley, em "Untitled: The House of Gender", tendo por base De Re Aedificatoria de Alberti, relaciona a invenção da privacidade com uma nova atitude perante o corpo: a arquitectura, mais do que defender o corpo, passaria a defender-se do corpo e das impurezas que este produz. Wigley insiste obsessivamente no tema do corpo, repetindo vinte vezes os termos body ou bodily em menos de três páginas, para concluir a interdependência entre espaço e sistemas de representação. Wigley refere-se à escassez, feita da economia e eliminação de todo o excesso (por sua vez associado ao prazer sensual), como uma forma de regular e restringir a arquitectura. Depois, alia esta ideia de "limpeza" ao controle masculino sobre o corpo feminino e associa-a ao tema da superfície branca - repetindo a expressão white surface ou sinónimos cerca de cinquenta vezes até ao final do artigo (1992, p.344-346). ${ }^{17}$ É com esta noção subversiva de despojamento que Mark Wigley chega a ver 'no apelo totalitarista de Le Corbusier ao branqueamento da arquitectura, um paradoxal programa de ornamentação'

(Barata, 1997, p.37)..$^{18}$

A noção de escassez regressa agora associada a um discurso de controlo com contornos ainda mais duros e simultaneamente mais incertos. A normativa da escassez, que parecia ser um atavismo português, vê-se aumentada a outros domínios - não exclusivamente portugueses.

\section{3}

Em Influx assumia-se que, apesar de tudo, a escassez não deixava de estar presente nas propostas das gerações mais novas; essa escassez foi associada a resquícios de formas de 'policiamento ideológico das fronteiras de uma determinada tradição' (Gadanho, 2003, p.155). Mas quando Influx se transformou em Metaflux, levando a Itália dez 
dos quinze arquitectos que tinha mostrado em Portugal (e acrescentando apenas um), a escassez passa a ser encarada de um modo diferente.

'Metaflux traduz uma resposta específica ao tema Metamorphs. A partir do contexto português seria insensato procurar responder ao tema que Kurt Forster lançou para a nona edição da Bienal com uma abordagem de carácter tecnológico ou formal. A realidade portuguesa não alberga esse discurso. A escassez de meios e a resposta poética reducionista encontrada pelos arquitectos portugueses para se adaptarem historicamente a uma realidade periférica não comporta elaborações em que a metamorfose assuma um protagonismo evidente.'

(Gadanho e Pereira, 2004, pp.19-23, 21)

Aquela proposta de arquitectura Influx, exposta no silo do Norte Shopping do Porto, que parecia estar no limite de abandonar a escassez, enuncia-a agora dentro de uma poética reducionista perante a Bienal de Veneza. Aqui, Metaflux reconduz a escassez para o lugar de condição. Montando e desmontando o discurso ideológico e academizado da escassez-prescrição. A escassez, em Portugal, é ideológica e real; condição e linguagem. Valida todos os discursos, anulando-os por isso.

Por exemplo, se noutros países, o uso da cal ou do reboco pintado de branco pode significar, um acerto (mais ou menos formal) com o Movimento Moderno, em Portugal, de facto, confunde-se com a simples utilização de um material com sentido de realidade e eficácia construtiva, e que entronca (por vezes de forma equívoca) na linguagem e na tradição.

Interessa a este propósito referir que Távora, no seu opúsculo, nunca associa o espírito da verdade à "perfeição imaculada" da lisura ou da cal. E em 1963, na memória descritiva da Escola Primária do Cedro, chega mesmo a clarificar a impossibilidade de se atingir o objecto puro, limpo e totalmente racional exaltado em "Le Lait de Chaux; La loi du Ripolin".

'Durante anos eu pensei a Arquitectura como qualquer coisa de diferente, de especial, de sublime e extraterreno, qualquer coisa assim como uma intocável virgem branca, tão sublime, tão ideal [...] a arquitectura aparece-me agora como uma grande força, força nascida da Terra e do Homem, presa por mil fios aos cambiantes da realidade, [...]. Não se trata, em verdade, de uma intocável e eterna virgem mas de uma pequena e simples obra feita por homens para homens.'

(Trigueiros, 1993, p.86)

A arquitectura surge, não como algo intangível e próprio dos espíritos elevados, mas como coisa simples, presa à realidade toda da vida. E apesar de Távora reivindicar uma arquitectura feita a partir dessa realidade de homens para homens como descoberta recente 
em 63, o seu edifício/'organismo vivo' em 47, tem já um arrebatamento diferente daquele 'organismo vivo' exaltado por Le Corbusier em 1925.

'Uma Arquitectura tem qualquer coisa de cada um porque ela representa todos, e exactamente será grande, forte, viva na medida em que cada um possa rever-se nela como um espelho denunciador das suas qualidades e defeitos. A colaboração será da maior parte para que possa satisfazer a todos; impõe-se um trabalho sério, conciso, bem orientado e realista, [...].'; 'No estudo do meio português deveríamos atender aos dois elementos fundamentais, o Homem e a Terra, no seu presente e no seu desenvolvimento histórico, influindo-se mutuamente [...].'

(Távora, 1947, p.10)

Neste sentido, se Távora (supostamente a entrar no esquecimento das novas gerações) podia parecer estar nos antípodas da contemporaneidade, entra agora numa espécie de consonância. O Problema da Casa Portuguesa não é movido pela tentativa de estabelecer um repertório de fórmulas (afinal esse era o problema). Távora expressa um asco pelo "tradicional", enquanto "cartilha de intenções', numa atitude semelhante àquela de Pedro Gadanho quando se refere à 'pesada, autónoma e academizada tradição arquitectónica portuguesa'. Aquilo que Gadanho identifica como uma atitude nova: 'contra a tendência uniformizadora dos preceitos que localmente ditaram uma "escola do fazer" dá-se uma fuga para a frente', é afinal a necessidade de 'seguir em frente' que Távora já em 47 sugeria ser a via possível (2004, p.43; 1947, p.12).

\section{4}

Os arquitectos escolhidos para integrar a exposição Metaflux foram agrupados em duas gerações com cerca de meia década de diferença, 'a geração x' e a 'geração y'. Seriam as diferenças geracionais que iriam responder ao tema lançado por Kurt W. Forster, Metamorph. À falta de abordagens com forte 'carácter tecnológico ou formal', esta era a resposta encontrada. Assim, as 'mutações' e inconformismos verificados na discrepância entre uma geração e outra eram em si a própria concretização da metamorfose. Metaflux questionava desta forma, sobretudo a partir das propostas de última-geração-y, 'se não serão novas identidades, simultaneamente mais gerais e transversais, as que ganham palco e definem novos sentidos.' Referem-se 'mudanças mais genéricas no tecido daquelas identidades supranacionais que, progressivamente, se substituem às tradições localmente cultivadas' (Gadanho e Pereira, 2004, pp.19-23; 21; Gadanho, 2004, p.35).

No entanto, há algo de paradoxal nesta perspectiva. Por um lado, salienta-se o gradual afastamento em relação à especificidade portuguesa; por outro, na repulsa, constrói-se uma exposição assente na ideia-em-si desse afastamento. Constrói-se um discurso crítico à posteriori, que teoriza aquilo que se verificou na prática, que encontra 
os processos de importação/acomodação, e que lembra as 'invariantes da arquitectura portuguesa' observadas por Alexandre Alves Costa. ${ }^{19}$ Não foi escolhido um tema propositivo, não se distingue nenhuma intenção realmente nova; extrema-se apenas um estatuto não-nacional (europeu, no mínimo) que surge aparentemente como uma fatalidade, algo de incontornável e resultante dos fluxos incontornáveis dos jovens contemporâneos.

Metaflux parece convergir directamente naquilo de que se quer afastar. A ambiguidade da questão escassez é ao mesmo tempo um módico indício de como para deixar de existir "identidade" não é suficiente afirmar a "não-identidade" (assim como para existir não basta afirmar que existe). Como se o facto da individualidade não desaparecer com o fumo, que deve sobretudo despreocupar aqueles que a defendem obsessivamente, tal como Távora (1947, p.12) tornou evidente, advertisse também os que estão afirmativos do seu (futuro) desaparecimento. ${ }^{20}$

5

Quando se lê que 'hoje, em Portugal, já não é preciso ser um Távora com uma bolsa da Gulbenkian na mão, para viajar pelo estrangeiro e entrar na World Wide Web do discurso arquitectónico' (Safran, 2003, p.14), sente-se que Távora é o digno representante do jovem português em movimento e ao mesmo tempo a representação daquilo que se encontra ultrapassado. Os contactos que se verificam existir entre o texto de Távora e estes fluxos - no inconformismo, na vontade de internacionalização, na rejeição de normas fixas pré-estabelecidas, no desejo de reforma do ensino, ou na tentativa de se encontrarem soluções dentro de uma situação de escassez teórica e tecnológica - incita a tentar perceber se o interesse d'O Problema da Casa Portuguesa estará para lá dos conflitos e dos consensos. As semelhanças conduzem-me a levar em devida consideração esta "nova" crítica: a interrogar em profundidade uma certa clonagem académica, auto-referenciada e masculina, afastada quer daquilo que se faz internacionalmente, quer daquilo que é possível fazer dentro da sua própria realidade. Neste sentido, académico pode ser entendido, não só como aquilo que é acriticamente normativo, protocolar, mas também como aquilo que está afastado do contexto em que se insere. Mas nesta perspectiva de académico (enquanto afastado da realidade) qual é o acertado sentido da exposição que foi representar Portugal a Veneza?

É como se face à brutal realidade, por um lado, e pelo anquilosado contexto cultural dessa realidade' (Bandeirinha, 1993, p.113), por outro, esta exposição criticasse o refúgio encontrado no imaginário do Inquérito, ridicularizando qualquer hipótese de ainda-semelhança e debruçando-se sobre uma exterioridade. ${ }^{21}$ As tentativas de aproximação da realidade Portuguesa a uma realidade-genérica, os projectos de Pedro Bandeira, ou as fotografias e vídeos de Augusto Alves da Silva, ou de Diogo Lopes e Nuno Cera para Metaflux, ou de Daniel Blaufuks 
para a instalação Paisagens Invertidas, Les Yeux Qui ne Voient Pas, ${ }^{22}$ revelam um ainda-fascínio por essa realidade ao mesmo tempo que a representam e transfiguram; situando-nos, eventualmente, e a propósito da 'viagem visual e conceptual para Oriente' enunciada por Paulo Varela Gomes, perante uma 'estetização catastrofista'; uma 'estetização sistemática' através da imagem (2003, p.25).

Esta lacuna, eventualmente intransponível, a da ausência de cartografias portuguesas, frequentemente assinalada pelo arquitecto Nuno Portas, ${ }^{23}$ parece dar sentido ao opúsculo de Távora onde apela ao estudo do 'meio português'. Para Távora, as soluções a encontrar não estariam (apenas) no fascínio pelo outro: Távora-fisiólogo apela à circunstância portuguesa; 'colocando luvas perante as ideologias', procura recuperar o sentido numa intuição 'essencialmente esquecida', numa unidade entre o pensamento e a Vida. ${ }^{24}$ Não opõe contemporaneidade/Europa a Portugal/passado (como se de regiões ou tempos diferentes se tratassem), 'consubstancia a condição espacial - nós portugueses - com a condição temporal - nós contemporâneos tornando-as indissociáveis' (Bandeirinha, 1993, p.89). Se "ser português", como teoriza Távora, não passa por negar "ser-se contemporâneo": "ser contemporâneo" também não deveria passar por negar "ser-se português". Neste sentido, Távora é Influx e Exflux ao mesmo tempo.

6.

O termo 'recente' para significar arquitectura produzida por aqueles que nasceram mais tarde é bastante discutível. Távora, ao contrário de separar 'novas audiências' e 'ideólogos' - 'os gate-keepers da disciplina' (Gadanho, 2004, p.43) - sugerindo a antiguidade dos segundos, oferece outro tipo de resistência à homogeneização que se instalava no meio arquitectónico português.

\section{'Abrem-se perante nós, novos ou velhos armados de um espírito novo, horizontes vastíssimos, campos férteis de possibilidades, [...].'; 'Todos podemos colaborar e é errado pensar que apenas aos arquitectos compete a resolução do caso, [...].'}

(Távora, 1947, pp.9-10)

Sugere uma lógica de simultaneidade, de sobreposição de estados: num 'propósito de não aceitar um só caminho pelo simples facto de ele se apresentar a si próprio como único' (Costa, 1990, p.10). ${ }^{25}$ No entanto, se a diversidade pode estar, por exemplo para Alexandre Alves Costa, na lógica de continuidade da arquitectura portuguesa, ${ }^{26} \mathrm{em}$ Metaflux, a diversidade é antes um sinal dos novos tempos da Europa. A diversidade y significou, face ao minimalismo de $\mathrm{x}$, um novo modelo de internacionalismo 'contra a tendência uniformizadora dos preceitos que localmente ditaram uma "escola" do "fazer"' - 'após uma geração intermédia que se dedicou a perpetuar ciosamente as fronteiras daquilo que era considerado o 'reduto de segurança' da arquitectura 
portuguesa, é só em gerações mais jovens que a ideia de abertura e miscigenação com o exterior começará a ganhar contornos influentes' (Gadanho e Pereira, 2004, pp.19-23; Gadanho, 2004, pp.43, 37).

Mas: a diversidade reivindicada em Metaflux será por si só sinónimo de superação de códigos pré-estabelecidos? Jorge Figueira refere que 'a apresentação dos dez ateliers seleccionados é feita de modo fragmentário, colocando toda a ênfase no instante formal mais do que na legibilidade dos projectos': 'o que Metaflux convoca é essencialmente uma certa performance gráfica que os projectos possam atingir': 'o próprio arquitecto está suspenso em fotografias que pairam sobre a obra, remetendo para uma futura capa da El Croquis' (2004). As observações de Figueira como que corroboram a pertinência das questões que aqui se levantaram. Seria todavia interessante verificar até que ponto as obras se relacionam ou não com os discursos que as veiculam.

'Seguem caminho errado os que preconizam o retorno a estilos que já foram ou os que pelo figurino "da moda" pretendem criar em Portugal uma arquitectura e um urbanismo modernos; qualquer destas atitudes revela um tão perigoso quanto inútil diletantismo plástico [...]. $\mathrm{O}$ "estilo" não conta; conta, sim, a relação entre a obra e a vida.'

(Távora citado por Tostões, 1997, p.46) ${ }^{27}$

\section{O Corporema da Casa Portuguesa}

A capacidade d'O Problema da Casa Portuguesa nos fazer pensar depende da forma como recolocarmos a problemática que está suspensa no seu título. Trata-se sobretudo de saber estabelecer o movimento, saber obter a repetição. Um aspecto importante da possibilidade de o reapropriar, de o repetir, é essa em-si-só-possibilidade: é que esta participa num pensamento que procura nem a contestação infinita nem a resignação infinita. ${ }^{28}$ Prefere vê-lo ultrapassar as dicotomias $\mathrm{y} / \mathrm{x}$, vê-lo dirigir-se para essa espécie de desejo de unidade entendida como polémica expressão da complexidade. ${ }^{29}$ Ter a característica de corporema e simultaneamente de corpo de possivivis.

\section{'O corpo, em vez de ocupar uma posição tradicionalmente} monocentral, desdobrar-se-ia em multicentralidades, sendo cada uma das novas posições ocupada por um corporema.'

(Silva, 1999, p.55)

O Problema da Casa Portuguesa apesar do tom firme de manifesto deixa em aberto um Problema. Encerra assim uma contradição interessante: estabelece um conjunto de princípios de verdade e simultaneamente suspende a verdadeira condição da sua aplicação na realidade. 
$1 \rightarrow$ "Correspondances", "Spleen et Ideal"

$2 \rightarrow$ Estudos Avançados em Arquitectura, Território e Memória, darq, FCTUC, 2002-2004 (EAATM)

$3 \rightarrow$ Ensaio publicado no semanário Aléo em 10 de Novembro de 1945; para este trabalho foi utilizada a versão refundida e aumentada pelo autor publicada em 1947

$4 \rightarrow$ Vient de paraître, cartaz publicitário para Vers une Architecture, 1923, v. Colomina (1998, pp.118-128,122)

$5 \rightarrow$ No âmbito $\operatorname{EAATM~(v.~n.2)~}$

$6 \rightarrow$ Workshop com Adrian Forty, Teresa Cruz e Paulo Cunha e Silva, 1000 Plateaux, Experimenta, Lisboa; v. também Silva (1999)

$7 \rightarrow$ Influx ocorreu no âmbito da programação da Fundação de Serralves para o Silo Norte Shopping; Metaflux constituiu a Representação Oficial Portuguesa na 9a Bienal de Veneza de 12 de Set. a 7 de Nov. 2004, org. Instituto das Artes

$8 \rightarrow$ Bandeirinha, "Um manifesto edificante"

$9 \rightarrow$ Keil do Amaral; “Uma Iniciativa Necessária” in Arquitectura, n¹4, Lisboa, Abr. de 1947, citado por Tostões (1997, p.25), v. também Tostões (1997, pp.49-50); Amaral, F. K. (coord.) (1988): Arquitectura Popular em Portugal. Lisboa: Associação Arquitectos Portugueses [1961]

$10 \rightarrow$ v. n.7

$11 \rightarrow$ v. n.7

$12 \rightarrow$ v. n.7; Gadanho (2004, pp.47, 41, 39)

$13 \rightarrow$ Gadanho cita também Carvalho (2003)

$14 \rightarrow$

$15 \rightarrow$ Távora (1947, p.11); Bandeirinha (1993, pp.91,113)

$16 \rightarrow$ Corbusier (1996, pp.185-195, 193): ‘Le Blanc de chaux est absolu, tout s'y détache, s'y écrit absolument, noir sur blanc; c'est franc et loyal.' ; Le Blanc de chaux est extrêmement moral.'; Távora (1947, p.8) escreve: 'uma íntima e constante força que unifica e prende entre si todas as formas, fazendo de cada edifício um corpo vivo, um organismo com alma e linguagem próprias.' $17 \rightarrow$ Wigley (1992, p.352) cita Alberti, De Re Aedificatoria, livro II: 'As in the house, excess is understood as sensuality, an improper pleasure to be regulated and displaced into the intellectual pleasure of the regulations themselves: the architect should "condemn unruly passion for building: (...), while pleasure itself never fails to shun every excess." The building itself is subjected to the economic regime it enforces.'; ver também Wigley (1992, pp.347,333,350-354,365) $18 \rightarrow$ Ver também Wigley (2001)

$19 \rightarrow$ Alexandre Alves Costa, aulas de Identidade na História da Arquitectura de Portugal, EAATM (v. n.3), Out. 2004: 'Fazer toda a teoria à posteriori: isso é Portugal.'

$20 \rightarrow$ Este assunto remete para o paradoxo 'o nacionalismo é indissociável da ideia de se querer ser novo' referido por Alexandre Alves Costa (v. nota anterior) $21 \rightarrow$ Nuno Grande (2004, p.13) coloca a questão nos termos: 'Trata-se, por isso, de deixar de 'resistir' defensivamente contra a 'banalização' do mercado internacional da arquitectura, opondo-se-lhe uma visão localista e nostálgica; trata-se antes, de investigar e perceber como actua esse mesmo mercado global, para reflectir sobre a sua adaptabilidade local, (...).'

$22 \rightarrow$ A. A. da Silva, "A Nossa Liberdade"; P. Bandeira, "Projectos específicos para clientes genéricos"; D. Lopes e N. Cera, "Cimêncio Top 10+1, subúrbios e arredores de Portugal"; Metaflux (2004, pp.1-8; 169-176; 25-32); Paisagens Invertidas: representação de Portugal no XXI Congresso da União Internacional de Arquitectos em Berlim 2002

$23 \rightarrow$ Por exemplo nas aulas de Teoria Crítica do Urbanismo, EAATM (v. nota 3 ), Jan. 2004

$24 \rightarrow$ Sobre a ideia do fisiólogo ver Deleuze (2000a, pp.17, 57-58), a propósito de Nietzsche

$25 \rightarrow$ Alexandre Alves cita Eduardo Lourenço para se referir a Siza.

$26 \rightarrow$ Costa (1990, p.10): 'Depois, a lógica de continuidade na arquitectura portuguesa está, sobretudo, no manuseamento da diversidade de linguagens, no carácter temporário e local dos consensos e não no objectivo único da persistência de um idêntico nacional.' 
$27 \rightarrow$ Fonte original: "Fernando Távora, entrevista" in A Arquitectura Portuguesa,

$\mathrm{n}^{\circ} \mathrm{s} 3$ e 4, Lisboa, Abr. 1953

$28 \rightarrow$ Aproprio, em parte, Deleuze (2000b, p.48): 'fazer da própria repetição algo

de novo; ligá-la a uma prova, a uma selecção, a uma prova selectiva; colocá-la

como objecto supremo da vontade e da liberdade'.

$29 \rightarrow$ A propósito de Álvaro Siza, Alexandre Alves Costa (1990, pp.20-22) escreve:

' (...) Siza não propõe um edifício que prefigure ou potencie a nova cidade do

futuro mediada por alguma imagem globalizante, antes vai manifestar o seu desejo

de unidade entendida como polémica expressão da complexidade, iniciando a sua

metódica busca de uma razão que não reprima nenhum dos elementos que constituem

a realidade (...).'; Algumas relações ainda com Deleuze (2000a, p.18): 'Unidade

complexa: um passo para a vida, um passo para o pensamento. Os modos de vida

inspiram maneiras de pensar, os modos de pensar criam maneiras de viver. A vida

activa o pensamento e o pensamento, por seu lado, afirma a vida.'

Referências Bibliográficas

Bandeirinha, J. A. O. (1996). Quinas Vivas.

Porto: FAUP [2 ${ }^{\text {a }}$ ed.; 1993$]$

-

Barata, P. M. (1997). A arte de construir no nosso tempo. In L. Trigueiros (ed.). Álvaro Siza 1954-1976 (pp.37-41). Lisboa: Editorial Blau

Baudelaire, C. (1993). As Flores do Mal.

Lisboa: Assírio e Alvim [1861]

Carvalho, R. (2003). A Arte da Oscilação.

In Gadanho e Pereira (pp.164-171)

Colomina, B. (1998). Privacy and Publicity.

Modern Arquitecture as Mass Media. Cambridge,

Massachusetts: The MIT Press [ $4^{\text {a }}$ ed.; 1996]

-

Corbusier, L. (1996). L'Art Décoratif D'Aujourd'hui. Paris: Flamarion [1925]

Costa, A. A. (1997). Álvaro Siza. In L. Trigueiros (ed.). Álvaro Siza 1954-1976 (pp.9-36).

Lisboa: Editorial Blau [1990]

Costa, A. A. (1993). Legenda para um Desenho de Nadir Afonso. In Trigueiros, L. (ed.) (pp.17-20)

Deleuze, G. (2000b). Diferença e Repetição, Lisboa: Relógio D’Água [1968]
Deleuze, G. (2000a). Nietzsche.

Lisboa: Edições 70 [1965]

-

Figueira, J. (2004). Bienal de Veneza: O alargamento europeu. Público, 18 de Set. 2004

Gadanho, P. (2003). Escassez e Deslocação. In Gadanho e Pereira (pp.148-155)

Gadanho, P. (2004). Xvs.Y-NOT=Diversidade, Equações de identidade na arquitectura portuguesa recente. In Gadanho e Pereira (pp.33-47)

Gadanho, P. e Pereira, L. T. (coord.) (2003). Influx, Arquitectura Portuguesa Recente. Barcelos: Civilização

Gadanho, P. e Pereira, L. T. (conc.) (2004). Metaflux, duas gerações na arquitectura portuguesa recente, Barcelos: Civilização

Gomes, P. V. (2003). Viagem para o Oriente. In J. Figueira e A. V. Milheiro (coord.), Paisagens Invertidas, Les Yeux Qui ne Voient Pás (pp.11-30). Lisboa: Ordem dos Arquitectos

Grande, N. (2004). Internacionalismo crítico, o possível lugar de uma revista de arquitectura. NU, 18, Coimbra, 10-13
Safran, Y. (2003). Connoisseurs of Chaos. In Gadanho e Pereira (pp.12-14)

Silva, P. C. e (2004). Da metamorfose. In Gadanho e Pereira (pp.15-17)

Silva, P. C. e (1999). O Lugar do Corpo, Elementos Para Uma Cartografia Fractal. Lisboa: Instituto Piaget [1996]

Távora, F. (1947). O Problema da Casa Portuguesa, Lisboa: Manuel João Leal

Tostões, A. (1997). Os Verdes Anos na Arquitectura Portuguesa dos anos 50. Porto: FAUP [1994]

Trigueiros, L. (ed.) (1993). Fernando Távora. Lisboa: Editorial Blau

Wigley, M. (1992). Untitled: The Housing of Gender. In B. Colomina (ed.) Sexuality \& Space (pp.327-389). Nova lorque: Princeton University Press

Wigley, M. (2001). White Walls, Designer Dresses: The fashioning of Modern Architecture. Cambridge, Massachusetts: The MIT Press [1995] 